Article

\title{
Constitutive Modelling and Hot Workability Analysis by Microstructure Examination of GH4169 Alloy
}

\author{
Rongchuang Chen $\left.{ }^{(}\right)$, Zhizhen Zheng *, Jianjun Li and Fei Feng \\ State Key Laboratory of Material Processing and Die \& Mould Technology, Huazhong University of Science \\ and Technology, Wuhan 430074, China; crc@hust.edu.cn (R.C.); jianjun@mail.hust.edu.cn (J.L.); \\ fengfei@hust.edu.cn (F.F.) \\ * Correspondence: zzz@hust.edu.cn; Tel.: +86-136-1866-0011; Fax: +86-027-87543490
}

Received: 26 May 2018; Accepted: 6 July 2018; Published: 9 July 2018

\begin{abstract}
The relationships between hot deformation parameters and flow behaviour have attracted many researchers' attention for the past few decades, whilst precise constitutive modelling of GH4169 remained a problem, which seriously affected the process and microstructure control of alloys. In this work, a modified Arrhenius type model was introduced to describe the flow stresses of various compression conditions. The model showed high precision in flow stress prediction. In order to facilitate workability evaluation for engineering applications, the hot processing maps were established at the strain of $0.4 \sim 0.6$. The processing maps revealed an instability domain at $900 \sim 950{ }^{\circ} \mathrm{C}$ and $0.1 \sim 1 \mathrm{~s}^{-1}$, a high dissipation efficiency domain at 1060 1100 ${ }^{\circ} \mathrm{C}$ and $0.001 \sim 0.01 \mathrm{~s}^{-1}$, and a stable deformation domain for the rest of processing parameters. Microstructures of each domain were observed via optical microscope (OM) and electron backscattered diffraction (EBSD). The intriguing finding was that the microstructures morphology agreed well with the descriptions in "discontinuous mechanism", and incompletely recrystallized microstructures were found in the instability domain. Fully recrystallized microstructures were found in the stable deformation domain, and grain coarsen in the high dissipation efficiency domain. Optimal hot working conditions were suggested based on the microstructure analysis. This investigation contributed to a comprehensive understanding of the workability of GH4169.
\end{abstract}

Keywords: GH4169 alloy; deformation behaviour; processing maps; dynamic recrystallization; constitutive modelling; hot deformation

\section{Introduction}

The GH4169 is a nickel-based high temperature alloy, and it has been widely used in structural parts in petroleum, aerospace, and nuclear industry due to its excellent high temperature mechanical properties. Generally, the strength, toughness and fatigue performance can be optimized by microstructure refinement, which are in turn determined by hot processing parameters. However, the constitutive relationship of GH4169, although it has been investigated by some researchers [1-4], has not been precisely established, and the hot processing maps have not been constructed systematically based on microstructure examinations of different domains, which has caused difficulty in microstructure control in hot forgings.

The constitutive relationships of various nickel-based alloys have been established by many researchers. Bariani et al. [5] calibrated the stress-strain relationship of Nimonic 80A alloy using artificial neural networks, and a good agreement was achieved between calculated data and experimental data. Tsuchida et al. [6] applied the Kocks-Mecking model in constitutive modelling in tensile deformation of $25 \mathrm{Cr}-19 \mathrm{Ni}$ steel, and results showed that with minor modifications, the model could accurately describe the influences of temperature and strain rate. Kar et al. [7] 
proposed a physical-based flow stress model which took into consideration the microstructure evolutions, and the model was then verified by constitutive modelling of a nickel-based alloy, René104. Puchi-Cabrera et al. [8] modeled the stress-strain relationship of $20 \mathrm{MnCr} 5$ steel using internal state variable model, and results showed a satisfactory precision in prediction of stress, work-hardening, and work-softening. Zhang et al. [9] constructed the constitutive relationship of a nickel-based alloy based on the dislocation density theory and the dynamic recrystallization kinetics model. Specifically, for the GH4169 alloy, Yuan et al. [1] established the stress-strain relationship of GH4169 alloy for hot rolling process based on the Arrhenius equation. Also based on the Arrhenius equation, Li et al. [2] investigated the flow behaviour of GH4169 alloy under various temperatures and strain rates, and a flow stress model with an average error of $8.0 \%$ was established. Wen et al. [3] and Wei et al. [4] analyzed the flow behaviour of GH4169, and a flow stress model based on the Arrhenius equation was also proposed. Although the constitutive relationships of GH4169 have been investigated by researchers via various methods [1-4], a more accurate model is still needed in engineering application of GH4169.

The hot processing maps were proposed to evaluate the hot workability of various alloys by considering the forging as a power dissipation system in which the energy input by the deformation work was balanced by the energy output by heating and microstructure transformation. Prasad et al. [10] constructed the processing map of Mg-3Sn-1Ca alloy in hot extrusion, and it showed different microstructure evolution behaviors in different domains of the processing map. Wang et al. [11] identified the recrystallization region and instability region of X-750 nickel-based superalloy by microstructure observations, and the optimum hot working parameters were proposed. Shi et al. [12] established the hot processing map of GH925, and results showed a stable domain and an instability domain existed. The processing maps of GH4169, although they have been investigated by some researchers $[13,14]$, have not been systematically constructed by microstructure examinations, and the microstructure evolutions of different domains were unclear, which has caused difficulty in microstructure optimization in hot forging.

This investigation aims to accurately establish the constitutive relationships which describe the flow behaviour under high temperature compressions, and to analyze the workability of GH4169 via microstructure observations. Thus, the constitutive relationships of GH4169 will be constructed using the modified Arrhenius equation, and the processing maps will be established. Representative microstructures in each domain of the processing maps will be examined via optical microscope and electron backscattered diffraction (EBSD) tests. Optimized hot working parameters will be proposed based on microstructure observations.

\section{Materials and Experimental Procedures}

\subsection{Materials}

The compositions of GH4169 were measured via X-Ray Fluorescence (XRF) on the apparatuses (XRF1800, Shimadzu Inc., Kyoto, Japan) and shown in Table 1. The accuracy of element content measuring was claimed to be within $\pm 0.01 \%$. The as-received material was in an annealed state with diameter of $300 \mathrm{~mm}$. The specimens for XRF tests were sampled from the ingot by wire-electrode cutting and turning to $33 \mathrm{~mm}$ in diameter and $12 \mathrm{~mm}$ in height. Then the specimens for XRF tests were polished according to conventional metallographic preparation method. The specimens for hot compressions were prepared by wire-electrode cutting and turning to the diameter of $6 \mathrm{~mm}$ and to the height of $9 \mathrm{~mm}$.

Table 1. Chemical compositions of the as-received GH4169 alloy.

\begin{tabular}{ccccccccc}
\hline Elements & $\mathbf{N i}$ & $\mathbf{C r}$ & $\mathbf{N b}$ & $\mathbf{M o}$ & $\mathbf{T i}$ & $\mathbf{A l}$ & $\mathbf{C}$ & $\mathbf{F e}$ \\
\hline Mass fraction $(\%)$ & 53.2 & 19.5 & 5.30 & 2.85 & 0.82 & 0.51 & 0.03 & Balanced \\
\hline
\end{tabular}




\subsection{Experimental Procedures}

Hot compressions were performed at the strain rates of $0.001,0.01,0.1$, and $1 \mathrm{~s}^{-1}$, and at the temperature of $900,950,1000,1050$, and $1100{ }^{\circ} \mathrm{C}$ on a thermal compression machine (Gleeble 3500, Dynamic Systems Inc., Austin, TX, USA). The compression temperatures were selected to cover the forging temperature range $\left(900 \sim 1050{ }^{\circ} \mathrm{C}\right)$ of this alloy [15]. The selection of strain rates has considered the usual strain rates in conventional die forging process. The temperatures were measured via a thermalcouple which was welded on the half height of the specimen surface. The thermal compression machine was able to adjust the punch position automatically to obtain constant strain rates. During the whole compression process, stress, strain, temperature, and displacement were recorded continuously and exported via a computer. In thermal compressions, the specimens were heated at $200{ }^{\circ} \mathrm{C} / \mathrm{min}$ to deformation temperatures, held for two minutes, deformed at constant strain rates, and water quenched to $25^{\circ} \mathrm{C}$ to obtain the high temperature microstructures. The stress-strain curves underwent noise reduction. The schematic of the compression experiments was illustrated in Figure 1.

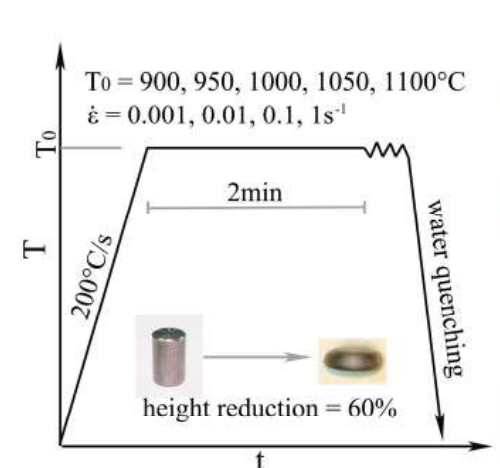

(a)

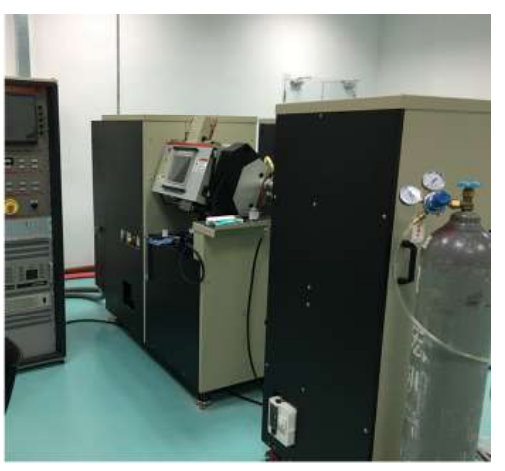

(b)

Figure 1. Schematic of the experimental procedure (a) time-temperature curve; and (b) experiment device.

Etching was implemented to scrutinize the microstructures of specimen symmetry plane passing through the axis. The etchant containing $10 \mathrm{~mL}$ concentrated hydrochloric acid, $10 \mathrm{~mL}$ anhydrous ethanol, and $0.5 \mathrm{~g}$ copper chloride was used for metallographic sample preparation. The microstructures were photographed via an optical microscope (VHX-1000C, Keyence Co., Osaka, Japan).

Samples for electron backscattered diffraction (EBSD) tests were wire-electrode cut to the size of $3 \mathrm{~mm} \times 3 \mathrm{~mm} \times 1.5 \mathrm{~mm}$, mechanically polished, and then electrolytically polished. The electrolytic liquid contained $20 \% \mathrm{H}_{2} \mathrm{SO}_{4}$ and $80 \% \mathrm{CH}_{3} \mathrm{CH}_{2} \mathrm{OH}$ (volume fraction), and the operating voltage was $25 \sim 30 \mathrm{~V}$. The tests were carried out on a field emission scanning electron microscope (JSM7800F, Japan Electronic Co., Tokyo, Japan). The scanning step size varied from 0.15 to $1.0 \mu \mathrm{m}$ depending on the size of the photographed area. The acceleration voltage was $25 \mathrm{kV}$, the acquisition frequency $116.87 \mathrm{~Hz}$, and the sample tilt angle $70^{\circ}$.

\section{Results and Discussion}

\subsection{Flow Behaviour}

The stress-strain relationship of GH4169 in compressions are shown in Figure 1 by plotting the flow stress versus the true stain curve. At the initial stage, the material underwent work-hardening (WH) and dynamic recovery (DRV) softening due to dislocation motions. As the deformation went on, dislocation piled up at grain boundaries, which led to the nucleation of recrystallization and dislocation consumption. Therefore, a peak at a critical strain followed by a gradual drop was shown on the stress-strain curve. When dynamic recrystallization completed, the effect of WH and DRV softening were balanced, and then the stress was stable. It could be seen from Figure 2 that a slight increase was found in the final stage because of the drum effect of specimen. 


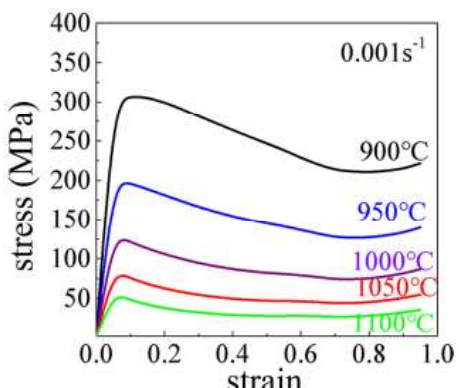

(a)

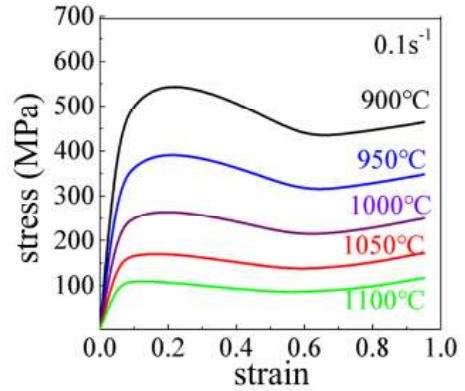

(c)

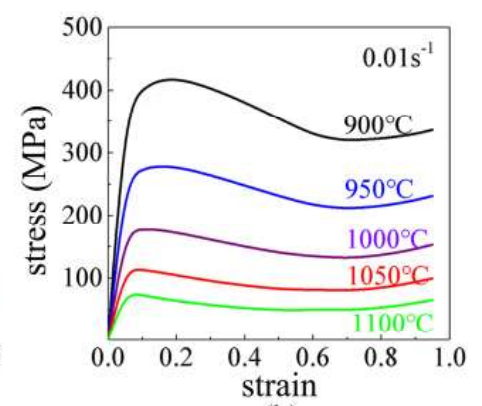

(b)

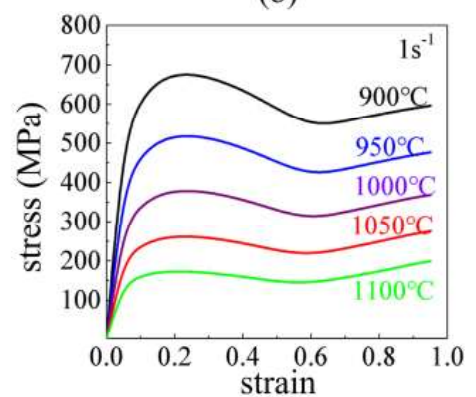

(d)

Figure 2. Stress-strain relationship of GH4169 compressed at (a) $0.001 \mathrm{~s}^{-1}$; (b) $0.01 \mathrm{~s}^{-1}$; (c) $0.1 \mathrm{~s}^{-1}$; (d) $1 \mathrm{~s}^{-1}$.

\subsection{Constitutive Modelling}

A precise constitutive model of GH4169 should be able to describe the effect of strain, strain rate, and temperature on flow stress, whilst in the Arrhenius model [16], the flow stress was independent of strain. Therefore, the Arrhenius model needed to be improved to provide a better description of the flow behaviour of GH4169. The strain rate $(\dot{\varepsilon})$ could be expressed as:

$$
\dot{\varepsilon}=A \sinh (\alpha \sigma)^{n} \exp (-Q / R T)
$$

where $A$ and $\alpha$ were material constants, $n$ the stress index, $Q$ the thermal activation energy in $\mathrm{J} / \mathrm{mol}, R$ the gas constant which equaled $8.31 \mathrm{~J} /(\mathrm{mol} \cdot \mathrm{K}), T$ the temperature in $\mathrm{K}, \sigma$ the flow stress in MPa. In Equation (1), at a certain strain, the value of $A, \alpha, n$, and $Q$ could be determined via liner regressions [17]. Then fifth-order polynomial fittings could be employed to describe the relationships of $A, \alpha, n$, and $Q$ with varying strain. The values of $A, \alpha, n$, and $Q$ in each fitting $(F)$ were expressed as:

$$
F=x_{0}+x_{1} \varepsilon+x_{2} \varepsilon^{2}+x_{3} \varepsilon^{3}+x_{4} \varepsilon^{4}+x_{5} \varepsilon^{5}
$$

where $x_{0} \sim x_{5}$ were coefficients, whose values were shown in Table 2 . The calculated and fitted values of $\ln (A), \alpha, n$, and $Q$ were shown in Figure 3a. It could be seen that the values of $\ln (A), n$, and $Q$ followed a similar trend. Take the value of $Q$ for example, as shown in Figure 3b, a dramatic decrease of hot deformation activation energy from $\sim 900$ to $500 \mathrm{~kJ} / \mathrm{mol}$ could be found as the strain increased from 0 to 0.9 . Generally, the hot deformation activation energy of metal materials decreased with increasing strain in hot compressions, which was proved by the result of GCr15 steel by Yin et al. [18], and $300 \mathrm{M}$ steel by Zhang et al. [19], but the relationship between the hot deformation activation energy change and microstructure evolution was not clearly explained. At the initial stage, the hot deformation activation energy decreased because the atom motions were facilitated by the dynamic recovery softening effect. At a certain critical strain, dynamic recrystallization occurred, thus a part of deformation energy was consumed by recrystallization. The contradiction effects of dynamic recovery and dynamic recrystallization on activation energy led to a relative slow drop of hot deformation activation energy. At the last stage in Figure 3b, the drop of hot deformation activation energy was dominated by dynamic recovery since dynamic recrystallization was completed [20]. 


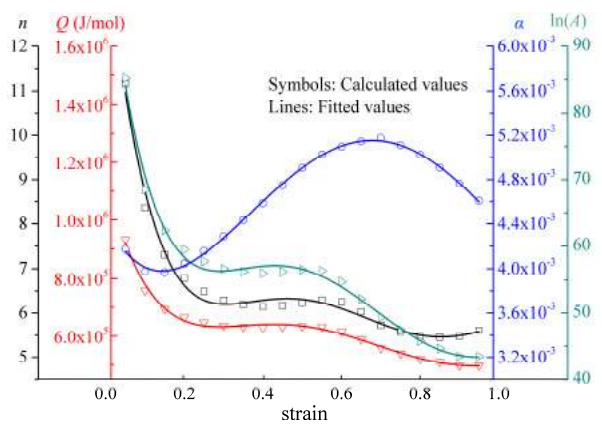

(a)

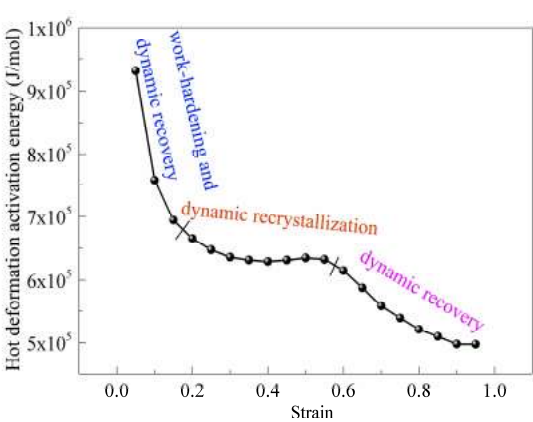

(b)

Figure 3. Model parameter analysis. (a) polynomial fitting of $A, \alpha, n$, and $Q$; (b) hot deformation activation energy analysis.

Table 2. Coefficients of the fifth-order polynomial fitting.

\begin{tabular}{ccccccc}
\hline Coefficients & $x_{0}$ & $x_{1}$ & $x_{2}$ & $x_{3}$ & $x_{4}$ & $x_{5}$ \\
\hline$n$ & $1.44 \times 10^{1}$ & $-8.31 \times 10^{1}$ & $3.13 \times 10^{2}$ & $-5.44 \times 10^{2}$ & $4.36 \times 10^{2}$ & $-1.30 \times 10^{2}$ \\
$\alpha$ & $4.41 \times 10^{-3}$ & $-6.78 \times 10^{-3}$ & $3.15 \times 10^{-2}$ & $-3.93 \times 10^{-2}$ & $1.50 \times 10^{-2}$ & $-4.17 \times 10^{-4}$ \\
$Q$ & $1.14 \times 10^{6}$ & $-5.32 \times 10^{6}$ & $2.06 \times 10^{7}$ & $-3.60 \times 10^{7}$ & $2.83 \times 10^{7}$ & $-8.15 \times 10^{6}$ \\
$\ln (A)$ & $1.05 \times 10^{2}$ & $-5.13 \times 10^{2}$ & $1.98 \times 10^{3}$ & $-3.46 \times 10^{3}$ & $2.72 \times 10^{3}$ & $-7.82 \times 10^{2}$ \\
\hline
\end{tabular}

The stress index $(n)$ reflected the relative creep rate of materials under certain stresses at high temperatures, and it may also be a reflection of the microstructure changes. As shown in Figure 3a, a dramatic decrease of the stress index from 11 to 6.5 at the strain range of 0 to 0.2 was followed by a slow decrease from 6.5 to 5.5 at the strain range of 0.2 to 0.9 . It was reported by Sun et al. [21] that there was a close relationship between the stress index value and the deformation mechanisms, and the stress index was between 5 and 8 when recrystallization was the main softening mechanism [18,19]. Hence, recrystallization may have occurred in GH4169 alloy as well, which should be further investigated by microscopic observations.

The comparisons of predicted and experimental flow stresses of GH4169 in compressions were shown in Figure 4. A good agreement was achieved, and the accuracy was evaluated in terms of maximum error, $7.3 \%$, and mean error, $2.6 \%$. The $\mathrm{R}$ value in representative of the confidence level was calculated to be 0.995 . The constitutive model was further validated by three other experiments, in which the compression temperature and strain rate were $920^{\circ} \mathrm{C}$ and $0.03 \mathrm{~s}^{-1}, 1020^{\circ} \mathrm{C}$ and $0.7 \mathrm{~s}^{-1}$, and $1020{ }^{\circ} \mathrm{C}$ and $0.03 \mathrm{~s}^{-1}$, respectively. It showed that the calculated flow stresses agreed well with the experimental flow stresses, and the mean error was $2.1 \%$. Therefore, the constitutive relationships of GH4169 could be precisely represented via models established in this investigation.

\subsection{Processing Maps}

The hot processing maps were proposed by Prasad et al. [22] to evaluate the hot workability of alloys by considering the forging as a power dissipation system in which the energy input was the deformation work, which was balanced by the energy output by heating and microstructure transformations. The energy input could be expressed as:

$$
P=G+J=\int_{0}^{\varepsilon} \sigma d \dot{\varepsilon}+\int_{0}^{\varepsilon} \dot{\varepsilon} d \sigma
$$

where $G$ was the energy consumed by plastic deformation, and $J$ was the energy consumed by microstructure evolutions. Therefore, a parameter representing the proportion of energy dissipated 
by microstructure evolutions in total input energy, $\eta$, namely power dissipation efficiency, could be calculated by:

$$
\eta=\frac{2 \frac{\partial \ln \sigma}{\partial \ln \dot{\varepsilon}}}{\frac{\partial \ln \sigma}{\partial \ln \dot{\varepsilon}}+1}
$$

An instability coefficient $(\zeta)$ was proposed to evaluate the deformation instability and expressed as:

$$
\zeta=\frac{\partial \log (\eta / 2)}{\partial \log (\dot{\varepsilon})}+\frac{\partial \ln \sigma}{\partial \ln \dot{\varepsilon}}
$$

It was argued that $\zeta$ was negative if deformation instability occurred. The values of $\eta$ and $\zeta$ for GH4169 could be determined at various strains according to Equations (4) and (5) by the constitutive model established in this investigation. Thus, the processing maps of GH4169 could be constructed at strains of $0.4,0.5$, and 0.6 , as shown in Figure 5. It could be seen that the deformation instability areas in Figure 5 all dropped at the upper-left corner. With increasing temperature and decreasing strain rate, the power dissipation efficiency increased from $\sim 20 \%$ to $40 \%$. The power dissipation efficiency at the lower-right corner slightly decreased with increasing strain.

The relationships between microstructure evolutions and the instability coefficient, $\zeta$, have been investigated by many researchers [10-14]. It was believed that in the deformation instability domain, in which $\zeta$ was negative, crack and localized material flow could be found. Therefore, the process parameters which dropped in the instability domain should be avoided. However, the relationships between microstructure evolutions and power dissipation efficiency, $\eta$, were not well established. Therefore, processing maps of GH4169 should be examined by microstructure observations to better explain the effect of power dissipation efficiency on hot workability. It could be seen from Figure 5 that the processing maps of GH4169 were featured by three domains: an instability domain at 900 950 ${ }^{\circ} \mathrm{C}$ and $0.1 \sim 1 \mathrm{~s}^{-1}$, a high dissipation efficiency domain at $1060 \sim 1100{ }^{\circ} \mathrm{C}$ and $0.001 \sim 0.01 \mathrm{~s}^{-1}$, and a stable deformation domain for the rest of the processing parameters. More explanations based on the observation results via optical microscope and electron backscattered diffraction were carried out afterwards.

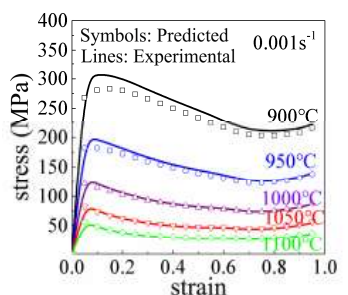

(a)

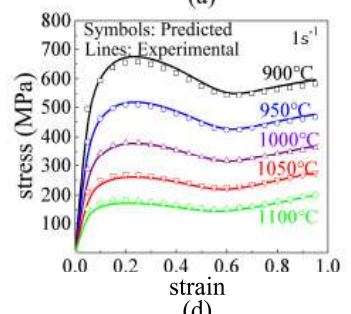

(d)

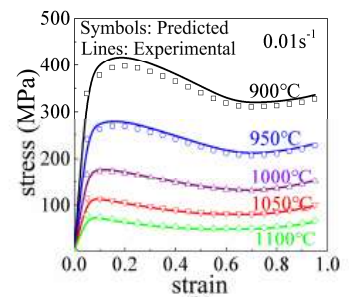

(b)

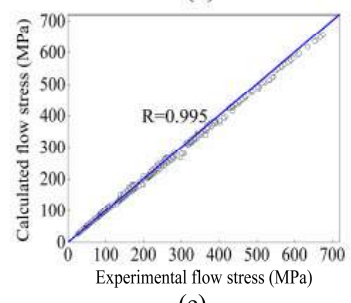

(e)

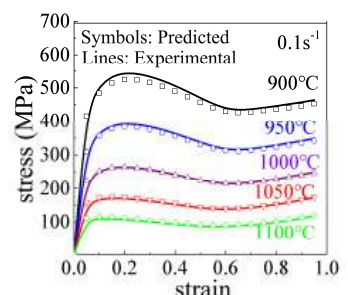

(c)

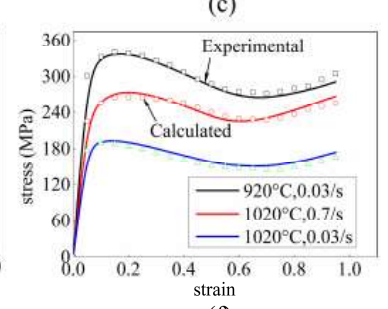

(f)

Figure 4. Comparison of predicted and experimental flow stresses of GH4169 compressed at various temperatures and strain rates of (a) $0.001 \mathrm{~s}^{-1}$; (b) $0.01 \mathrm{~s}^{-1}$; (c) $0.1 \mathrm{~s}^{-1}$; and (d) $1 \mathrm{~s}^{-1}$; (e) shows the scatter plot drawn by experimental and calculated flow stresses; (f) shows the validation of the model by three more experiments. 


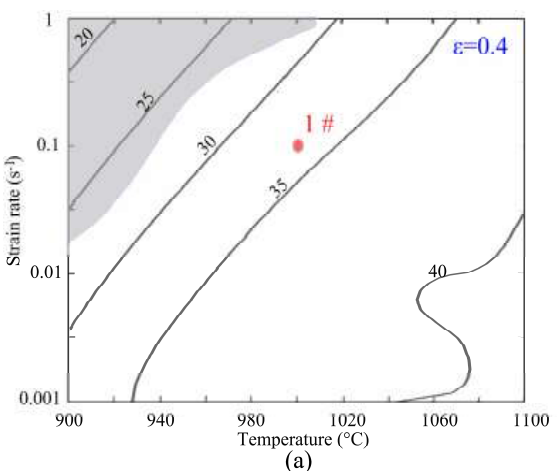

(a)

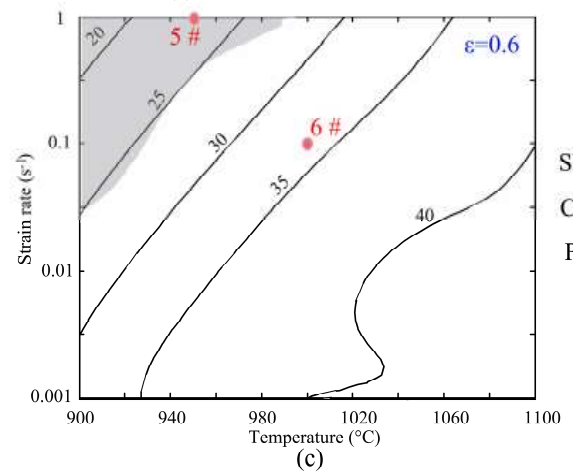

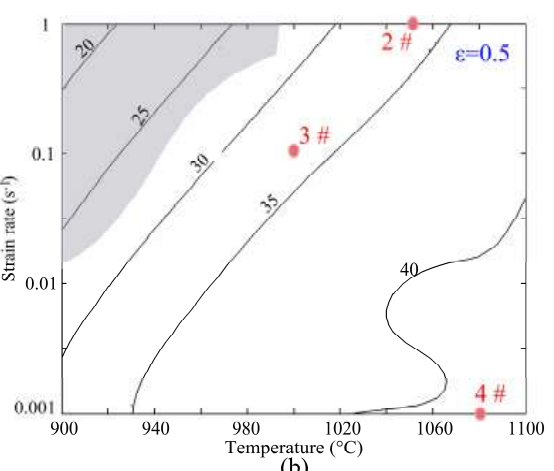

(b)

Shaded areas: deformation instability

Countours:power dissipation efficiency (\%)

Pink dots: process parameters for

microstucture examination

Figure 5. Hot processing map of GH4169 compressed to the strain of (a) 0.4 ; (b) 0.5 ; and (c) 0.6.

\subsection{Microstructure Examinations on Optical Microscope}

The microstructures of each domain were observed via an optical microscope, shown in Figure 6, and the processing conditions corresponded to the pink dots numbered 1 6 in Figure 5. The results of Figure $6 \mathrm{a}, \mathrm{c}, \mathrm{f}$ could be seen as the result of a continuous deformation under $1000{ }^{\circ} \mathrm{C}$ and $0.1 \mathrm{~s}^{-1}$, in which the strains were $0.4,0.5$, and 0.6 , respectively. The sizes of recrystallized grains were significantly smaller than that of initial grains. With increasing strain, the volume fraction of recrystallized grains increased gradually. The dissipation efficiency of Figure $6 b, \sim 33 \%$, was roughly equal to that of Figure $6 \mathrm{a}, \mathrm{c}, \mathrm{f}$. It could be seen from Figure $6 \mathrm{~b}$ that a much more homogeneous microstructure was obtained. The process parameters of Figure $6 \mathrm{a}-\mathrm{c}, \mathrm{f}$ dropped in the stable deformation domain. For the instability domain in which Figure 6e dropped, it could be seen that grains were equiaxed, but bigger magnification photos were needed to analyze whether recrystallization occurred in the material. For the high dissipation efficiency domain in which Figure $6 \mathrm{~d}$ dropped, it could be seen that recrystallized grains occurred at grain boundaries, but the strain may be insufficient for full recrystallization. Therefore, compressions at a greater strain needed to be carried out to check the possibility of full recrystallization.

\subsection{Microstructure Examinations by Electron Backscattered Diffraction}

In order to investigate the influences of process parameters on microstructure evolutions and better explain the processing maps of GH4169, the microstructures needed to be observed at higher magnifications. Besides, the results of Poelt et al. [23] and Mitsche et al. [24] showed that the optical microscope was not suitable for recrystallization analysis for nickel-based alloys with large strains ( 0.7), and the EBSD analysis was able to reveal the recrystallization mechanisms better. Therefore, EBSD tests of specimens under four compression conditions were carried out. 

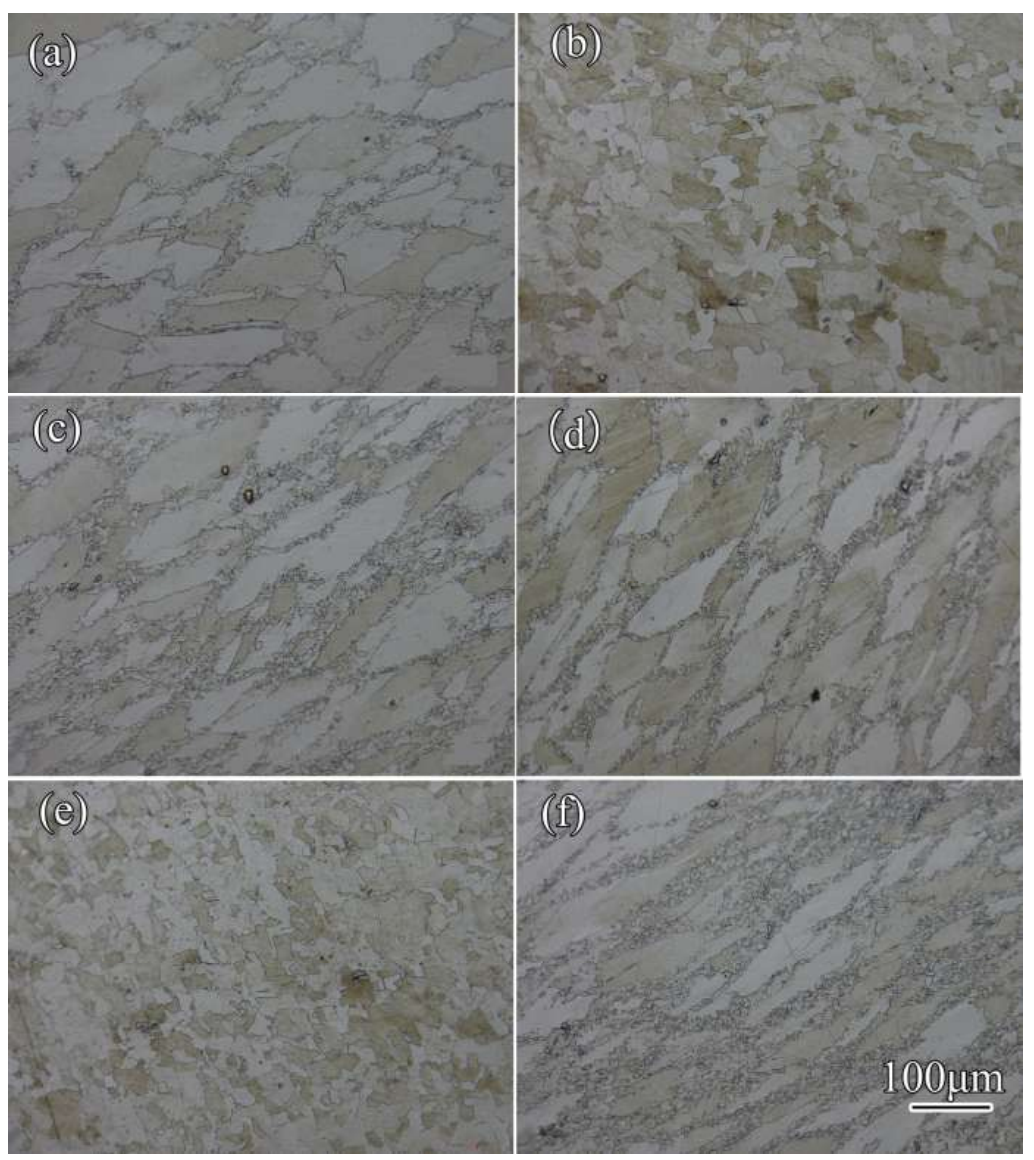

Figure 6. Microstructures of GH4169 compressed at (a) $1000{ }^{\circ} \mathrm{C}, 0.1 \mathrm{~s} \mathrm{~s}^{-1}, 0.4$; (b) $1050{ }^{\circ} \mathrm{C}, 1 \mathrm{~s}^{-1}, 0.5$; (c) $1000{ }^{\circ} \mathrm{C}, 0.1 \mathrm{~s}^{-1}, 0.5$; (d) $1080{ }^{\circ} \mathrm{C}, 0.001 \mathrm{~s} \mathrm{~s}^{-1}, 0.5$; (e) $950{ }^{\circ} \mathrm{C}, 1 \mathrm{~s}^{-1}, 0.6$; and (f) $1000{ }^{\circ} \mathrm{C}, 0.1 \mathrm{~s}^{-1}, 0.6$. The processing conditions corresponded to the pink dots numbered 1 6 \# in Figure 5.

The grain orientation maps were shown in Figure 7. The compression conditions were selected to investigate the microstructures at strain rates and temperatures boundaries. As could be seen in Figure 7a that the initial large grains were flattened due to compression, and grain boundaries were curved, around which lots of small grains were found. It was argued by Humphreys et al. [25] that the discontinuous recrystallization mechanisms of alloys were featured by curved grain boundaries and small recrystallized grains at initial grain boundaries. Therefore, the result of Figure 7a was a direct evidence of discontinuous recrystallization of GH4169. It could also be seen that the recrystallization was incomplete since several big initial grains still existed. The result of Figure 7a also represented the microstructures of the process conditions which dropped in the instability domain.

Figure $7 \mathrm{~b}, \mathrm{c}$ showed the microstructures of GH4169 compressed at $950{ }^{\circ} \mathrm{C}$ and $0.001 \mathrm{~s}^{-1}$, and at $1100{ }^{\circ} \mathrm{C}$ and $1 \mathrm{~s}^{-1}$. It showed that the microstructures on both conditions were fully recrystallized, which had undergone grain growth afterwards. The average grain sizes of Figure $7 \mathrm{~b}, \mathrm{c}$ were $6.4 \mu \mathrm{m}$ and $4.7 \mu \mathrm{m}$, respectively. The results of Figure $7 \mathrm{~b}, \mathrm{c}$ represented the microstructures of the stable deformation domain.

Figure $7 \mathrm{~d}$ showed the microstructures of GH4169 compressed at $1100{ }^{\circ} \mathrm{C}$ and $0.001 \mathrm{~s}^{-1}$. Note that the ruler length of Figure $7 d$ was different from the others. The grains were equiaxed with flat grain boundaries, indicating that dramatic grain growth had occurred after full recrystallization. The average grain size $(65.2 \mu \mathrm{m})$ and dissipation efficiency $(\sim 43 \%)$ was much greater than those of Figure $7 \mathrm{~b}, \mathrm{c}$. The result of Figure $7 \mathrm{~d}$ showed the representative microstructures of the high dissipation efficiency domain. 

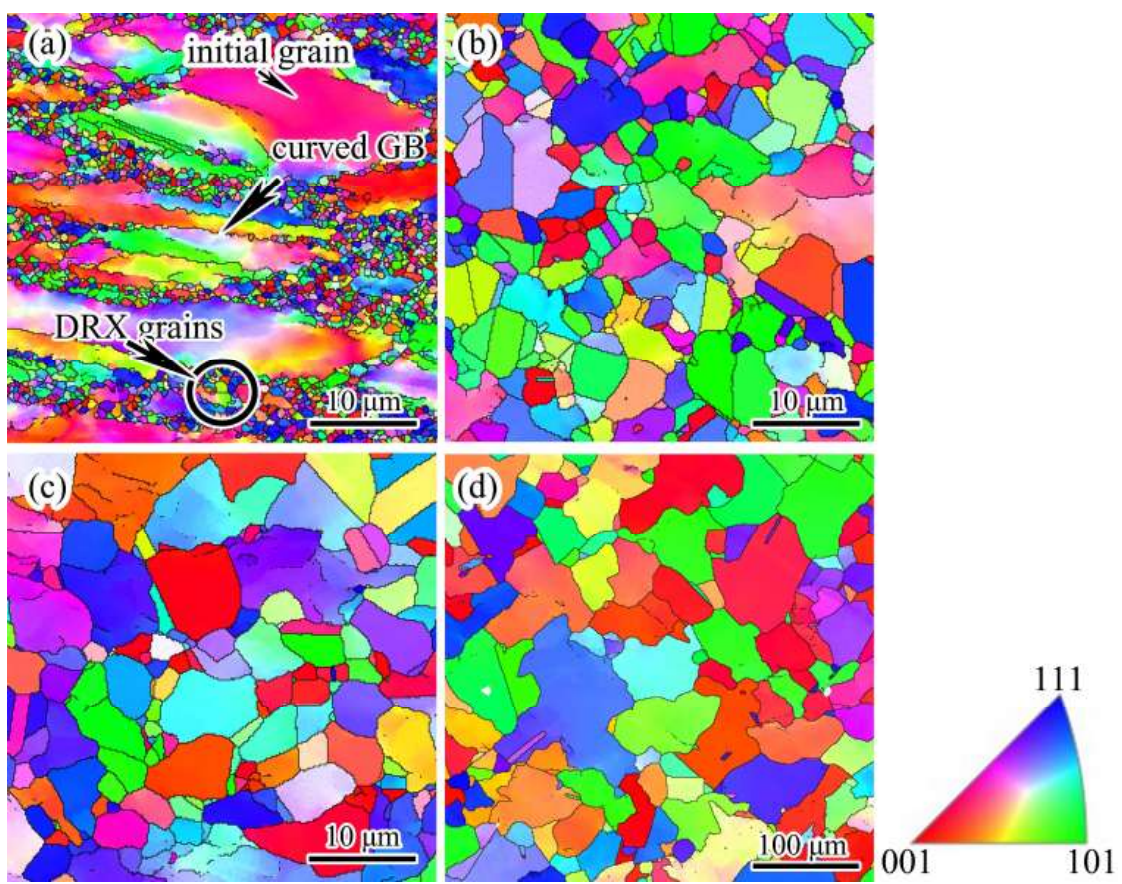

Figure 7. Grain orientation maps of GH4169 alloy compressed at (a) $950{ }^{\circ} \mathrm{C}, 1 \mathrm{~s}^{-1}, 0.9$; (b) $1100{ }^{\circ} \mathrm{C}$, $1 \mathrm{~s}^{-1}, 0.9$; (c) $950{ }^{\circ} \mathrm{C}, 0.001 \mathrm{~s}^{-1}, 0.9$; and (d) $1100{ }^{\circ} \mathrm{C}, 0.001 \mathrm{~s}^{-1}, 0.9$. The large angel grain boundaries $\left(\geq 15^{\circ}\right)$ were shown as black lines. Note that the ruler length of $(\mathbf{d})$ was different from the others. GB and DRX were abbreviations of "grain boundary" and "dynamic recrystallization", respectively.

Comparing Figure 7 with Figure 6, it could be seen that the EBSD result provided a much clearer description of the microstructures of GH4169 with large strains. It could also be inferred from Figures 5-7 that in order to get fully recrystallized fine grains, the recommended compression parameters should be in the stable deformation domain for which the power dissipation efficiency was between $30 \%$ and $35 \%$.

\section{Conclusions}

Based on the isothermal compressions and microstructure analyses, the following conclusions could be drawn:

(1) A constitutive model describing stress-strain relationship of GH4169 compressed at high temperatures was established based on the modified Arrhenius equation. The mean percentage error is $2.6 \%$, showing that a good agreement was achieved between the model predictions and the experimental results.

(2) The processing maps of GH4169 at the strain of $0.4,0.5$, and 0.6 were constructed. The processing maps were divided into three domains: an instability domain at the temperature range of $900 \sim 950{ }^{\circ} \mathrm{C}$ and strain rate range of $0.1 \sim 1 \mathrm{~s}^{-1}$, a high dissipation efficiency domain at $1060 \sim 1100{ }^{\circ} \mathrm{C}$ and $0.001 \sim 0.01 \mathrm{~s}^{-1}$, and a stable deformation domain for the rest of the processing parameters.

(3) The microstructures of each domain were observed by OM and EBSD. The EBSD result at $950{ }^{\circ} \mathrm{C}$ and $1 \mathrm{~s}^{-1}$ agreed well with the descriptions of "discontinuous mechanism". Incompletely recrystallized microstructures were found in the instability domain. Fully recrystallized microstructures were found in the stable deformation domain, and grain coarsen was found in the high dissipation efficiency domain. 
(4) In order to get fully recrystallized fine grains, the recommended compression parameters should be in the stable deformation domain for which the power dissipation efficiency was between $30 \%$ and $35 \%$.

Author Contributions: Conceptualization, R.C and Z.Z.; Methodology, R.C. and Z.Z.; Software, R.C.; Validation, R.C. and Z.Z.; Formal Analysis, F.F.; Investigation, R.C.; Resources, J.L. and F.F.; Data Curation, R.C.; Writing-Original Draft Preparation, R.C.; Writing-Review \& Editing, R.C. and F.F.; Visualization, R.C.; Supervision, Z.Z. and J.L.; Project Administration, Z.Z.; Funding Acquisition, J.L. and F.F.

Funding: This work was funded by the National Natural Science Foundation of China (No. 51435007, 51705169) and the China Postdoctoral Science Foundation (No. 2017M610472).

Acknowledgments: The authors would like to thank the faculties from the Advanced Manufacturing and Technology Experiment Center in Huazhong University of Science and Technology, and from Chengdu Century Mei Yang Technology Co. (http:/ / www.ceshigo.com) for the technical support on EBSD tests.

Conflicts of Interest: The authors declare no conflict of interest.

\section{References}

1. Yuan, K.; Wang, X.; Zhu, J.; Zhang, L.; Sui, F. Flow Stress Model of GH4169 Alloy in Hot Rolling Process. J. Anhui Univ. Technol. 2016, 2, 110-125. [CrossRef]

2. Li, M.Q.; Ju, W.B.; Lin, Y.Y.; Wang, X.J.; Niu, Y. Deformation behaviour of GH4169 nickel based superalloy in isothermal compression. Mater. Sci. Technol. 2008, 24, 1195-1198. [CrossRef]

3. Wen, D.X.; Lin, Y.C.; Chen, M.S. Study of Hot Deformation Behavior in GH4169 Superalloy. Adv. Mater. Res. 2013, 712-715, 658-661. [CrossRef]

4. Wei, J.H.; Dong, J.X.; Fu, S.H.; Yao, Z.H.; Zhang, M.C. Influence of deformation parameters on hot deformation behavior of GH4169 superalloy. Trans. Mater. Heat Treat. 2013, 34, 58-64.

5. Bariani, P.F.; Bruschi, S.; Negro, T.D. Prediction of nickel-base superalloys' rheological behaviour under hot forging conditions using artificial neural networks. J. Mater. Process. Technol. 2004, 152, 395-400. [CrossRef]

6. Tsuchida, N.; Tomota, Y.; Moriya, H.; Umezawa, O.; Nagai, K. Application of the Kocks-Mecking model to tensile deformation of an austenitic 25Cr-19Ni steel. Acta Mater. 2001, 49, 3029-3038. [CrossRef]

7. Kar, S.K.; Sondhi, S.K. Microstructure based and temperature dependent model of flow behavior of a polycrystalline nickel based superalloy. Mater. Sci. Eng. A 2014, 601, 97-105. [CrossRef]

8. Puchi-Cabrera, E.S.; Guérin, J.D.; Dubar, M. Constitutive description for the design of hot-working operations of a 20MnCr5 steel grade. Mater. Des. 2014, 62, 255-264. [CrossRef]

9. Zhang, P.; Yi, C.; Chen, G.; Qin, H.; Wang, C. Constitutive Model Based on Dynamic Recrystallization Behavior during Thermal Deformation of a Nickel-Based Superalloy. Metals 2016, 6, 161. [CrossRef]

10. Prasad, Y.V.R.K.; Rao, K.P.; Hort, N.; Kainer, K.U. Hot working parameters and mechanisms in as-cast Mg-3Sn-1Ca alloy. Mater. Lett. 2008, 62, 4207-4209. [CrossRef]

11. Wang, Y.; Pan, Q.; Song, Y.; Li, C.; Li, Z. Hot deformation and processing maps of X-750 nickel-based superalloy. Mater. Des. 2013, 51, 154-160. [CrossRef]

12. Shi, Z.; Yan, X.; Duan, C. Hot deformation behavior of GH4945 superalloy using constitutive equation and processing map. J. Alloys Compd. 2015, 652, 30-38. [CrossRef]

13. Kang, F.W.; Zhang, X.M.; Sun, J.F.; Zhao, J.L. Hot Deformation Behavior and Processing Map of a Nickel-Base Superalloy GH4169. Adv. Mater. Res. 2014, 834-836, 432-436. [CrossRef]

14. Ying, W.; Pan, Q.; Zhang, Y.; Shan, Q.; Li, Z. Hot deformation behavior and processing map of GH4169 superalloy. J Cent. South. Univ. 2014, 45, 3752-3761.

15. Semiatin, S.L. ASM Handbook Vol. 14 Forming and Forging; ASM International: Almere, The Netherlands, 2005; pp. 584-585.

16. Sellars, C.M.; Mctegart, M.J. Superplastic Deformation Behaviour and Microstructure Evolution of Near- $\alpha$ Ti-Al-Mn Alloy. Acta Metall. 1966, 14, 1136-1138. [CrossRef]

17. Yang, L.C.; Pan, Y.T.; Chen, I.G.; Lin, D.-Y. Constitutive Relationship Modeling and Characterization of Flow Behavior under Hot Working for Fe-Cr-Ni-W-Cu-Co Super-Austenitic Stainless Steel. Metals. 2015, 5, 1717-1731. [CrossRef] 
18. Yin, F.; Hua, L.; Mao, H.; Han, X. Constitutive modeling for flow behavior of GCr15 steel under hot compression experiments. Mater. Des. 2013, 43, 393-401. [CrossRef]

19. Zhang, X.; Huang, L.; Li, J.; Li, P. Flow behaviors and constitutive model of 300M high strength steel at elevated temperature. J. Cent. South Univ. 2017, 48, 1439-1447. [CrossRef]

20. Chen, R.; Guo, P.; Zheng, Z.; Li, J.; Feng, F. Dislocation Based Flow Stress Model of 300M Steel in Isothermal Compression Process. Materials 2018, 11, 972. [CrossRef] [PubMed]

21. Chaoyang, S.; Bing, S.; Chuanbiao, W.; Naiwei, Y.; Tianjun, M.; Wenliang, X.; Jing, Y. Experimental Investigation on High Temperature Creep Deformation Mechanism of BSTMUF601 Superalloy. Acta Metall. Sin. 2015, 51, 349-356. [CrossRef]

22. Prasad, Y.V.R.K.; Gegel, H.L.; Doraivelu, S.M.; Barker, D.R. Modeling of dynamic material behavior in hot deformation: Forging of Ti6242. Metall. Trans. A 1984, 15, 1883-1892. [CrossRef]

23. Poelt, P.; Sommitsch, C.; Mitsche, S.; Walter, M. Dynamic recrystallization of Ni-base alloys-Experimental results and comparisons with simulations. Mater. Sci. Eng. A 2006, 420, 306-314. [CrossRef]

24. Mitsche, S.; Poelt, P.; Microsc-Oxford, C.S.J. Recrystallization behaviour of the nickel-based alloy 80 A during hot forming. J. Microsc. 2010, 227, 267-274. [CrossRef] [PubMed]

25. Humphreys, F.J.; Hatherly, M. Chapter 1: Introduction. In Recrystallization and Related Annealing Phenomena, 2nd ed.; Elsevier: New York City, NY, USA, 2004; pp. 1-10.

(C) 2018 by the authors. Licensee MDPI, Basel, Switzerland. This article is an open access article distributed under the terms and conditions of the Creative Commons Attribution (CC BY) license (http:// creativecommons.org/licenses/by/4.0/). 